\title{
Caracterización histológica e inmunocitoquímica de la grasa infrapatelar de Hoffa
}

\author{
Edward Acero'-2, Luis Gustavo Celis², Fernando Lizcano², Jennifer Garay² \\ Juan Guillermo Ortiz ${ }^{3}$, German Carrillo4.
}

1. Facultad de Medicina, Universidad de La Sabana Grupo PROSEIM y Facultad de Medicina Universidad Militar. Grupo Morfología Médica.

2. Facultad de Medicina, Universidad de La Sabana Grupo CIBUS.

3. Clínica Universitaria de La Sabana.

4. Fundación Santafé.

Correspondencia: luis.celis@unisabana.edu.co

Recibido: 03-11-2011/ Aceptado: 30-12-2011

\section{Resumen}

El presente estudio tuvo como objetivo la caracterización histológica e inmunocitoquímica de la grasa infrapatelar de Hoffa $(\mathrm{GIH})$ en 12 pacientes intervenidos por artroscopia, meningoplastia o remplazo de rodilla. Las fibras elásticas estuvieron presentes en la grasa infrapatelar con distribución unidireccional fascicular, se plantea una relación funcional en la biomecánicas del movimiento articular de la rodilla. Por otra parte las pruebas de inmunocitoquimica arrojaron marcaje positivo para vimentina, marcador de células del tejido conectivo; células mesenquimales y negativo para el resto de los anticuerpos estudiados. Palabras clave: grasa infrapatelar, biomecánicas, vimentina, inmunocitoquimica, fibras elásticas.

\begin{abstract}
Histological and immunohistochemical characterization of infrapatellar Hoffa's fat

This study aimed to histological and immunohistochemical characterization of infrapatellar fat Hoffa $(\mathrm{GIH})$ in 12 patients undergoing arthroscopic, meningoplastia or knee replacement. Elastic fibers were present in the infrapatellar fat with unidirectional fascicular distribution, we propose a functional relationship in the biomechanics of the knee joint movement. Moreover Immunocytochemistry tests yielded positive staining for vimentin, a marker for connective tissue cells, mesenchymal cells and negative for other studied antibodies.
\end{abstract}

Key words: infrapatellar fat, biomechanics, vimentin, immunohistochemical, elastic fibers.

\section{Introducción}

La grasa infrapatelar es un tejido adiposo unilocular intracapsular pero extrasinovial en la articulación de la rodilla (1), anatómicamente se encuentra entre el borde del polo inferior de la rotula y el borde anterosuperior de la tibia, limitando anteriormente con la cara posterior del ligamento infrarotuliano y posteriormente con la membrana sinovial articular anterior de la rodilla, esta estructura se encuentra 
irrigada por las ramas de las arterias geniculadas superior e inferior (2). Una aproximación a su morfología microscópica que involucra la textura y su distribución se hace mediante imagenología estandarizada en el diagnostico anatomopatológico del condroma infrapatelar, la enfermedad de Hoffa postraumática y la fibrosis infrapatelar post artroscopía (3-6). Sobre la organización histológica de la grasa infrapatelar hay reportes en el diagnostico histopatológico de fibroma, hemangioma, condroma, lipoma e incluso en su detallada inervación en las rodillas artrósicas (711) pero no hay descripciones de la distribución y/o tamaño de fibras elásticas y menos en su caracterización inmunohistoquímica. Otro aspecto importante es que existen evidencias que sugieren que las células estromales multipotentes están presentes en tejido adiposo del humano adulto (12 y 13).

El propósito del estudio fue el realizar una caracterización histológica e inmunocitoquímica de la grasa infrapatelar de Hoffa.

\section{Materiales y métodos}

\section{Consentimiento informado y toma de muestras}

El consentimiento informado fue dado a conocer con antelación y aprobado por los pacientes que fueren intervenidos en la Clínica Universitaria de La Sabana y la Fundación Santafé.

A los pacientes se les extrajeron $1,5 \mathrm{~cm} * 2,3 \mathrm{~cm}$ cúbicos de grasa infrapatelar. Durante procedimientos de artroscopias, meningoplástias y reemplazos de rodilla.

\section{Características de los pacientes y procesamiento de muestras}

Las muestras extraídas se sumergieron en buffer de fosfato (PBS), se digirieron con colagenasa $0,5 \%$ en $\mathrm{PBS}$, a $37^{\circ} \mathrm{C}$ con agitación a $165 \mathrm{rpm}$ por 30 minutos. Luego se fijaron en formol al 10\%, se sometieron a histotécnica en parafina, cortes de 3 micras fueron coloreados con hematoxilina -eosina. Se observaron al microscopio óptico marca AXIOTAR 34-F para análisis de la distribución y grosor de las fibras, se midieron 120 fibras con micrómetro de cámara digital marca MOTIC al recorrer 5 campos en 100 X.
Una fracción de la muestra digerida fue centrifugada a $250 \mathrm{~g}$ por 10 minutos, posteriormente se le realizaron dos lavados con PBS separándose las células meseinquímales de los adipocitos maduros.

\section{Fenotipificación inmunohistoquímica}

Se realizó mediante un frotis directo en lámina porta objetos por cuadruplicado y se colorearon con azul de metileno para verificar su morfología, las 3 láminas restantes se realizaron con anticuerpos contra los filamentos intermedios de desmina, vimentina y citoqueratina y coloreados con diaminobencidina (Sigma, St. Luis) para su observación en el microscopio (Zeiss Imager A1, Alemania).

En la inmunofluorescencia se utilizo una lámina cubreobjetos con pozos delimitados por acrílico se dispusieron alícuotas de 20 microlitros de células de cultivo en medio F12. Se fijo la lámina luego con paraformaldehído al 4\%, durante 10 minutos, lavando después con PBS dos veces durante 5 minutos. Luego se adicionó una solución al 0,1\% de tritón X-100 y Solución Tampón Tris - TBS- a $\mathrm{pH}=7,6$ durante 5 minutos y se lavó dos veces con la solución de TBS.

Se procedió después a incubar lámina durante 15 minutos con una solución de bloqueo al 5\% de Suero Fetal Bovino y 0,001\% de tritón X-100 en TBS. Luego de la incubación se añadió el anticuerpo monoclonal primario anti-vimentina (Dako, Glostrup, Denmark) diluido 1:100 en una solución de TBS al 0,001\% de tritón X-100 y 5\% de Suero Fetal Bovino, incubando toda la noche a $4{ }^{\circ} \mathrm{C}$.

Al día siguiente se realizaron dos lavados con TBS, incubando a continuación con el anticuerpo secundario Alexa fluor 594 chicken anti-mouse IgG durante 45 minutos a temperatura ambiente y protegido de la luz. Una vez terminada la incubación se realizaron dos lavados con TBS y se procedió al montaje de los cubreobjetos en portaobjetos con medio acuoso Mowiol conteniendo colorante de Fluresceína marca Hoescht. Las láminas fueron observadas en un microscopio de fluoresencia (Nikon Eclipse 80i, Japón) con luz fluorescente, correspondiendo el marcaje de color verde intracelular como positivo a la presencia de vimentina. 


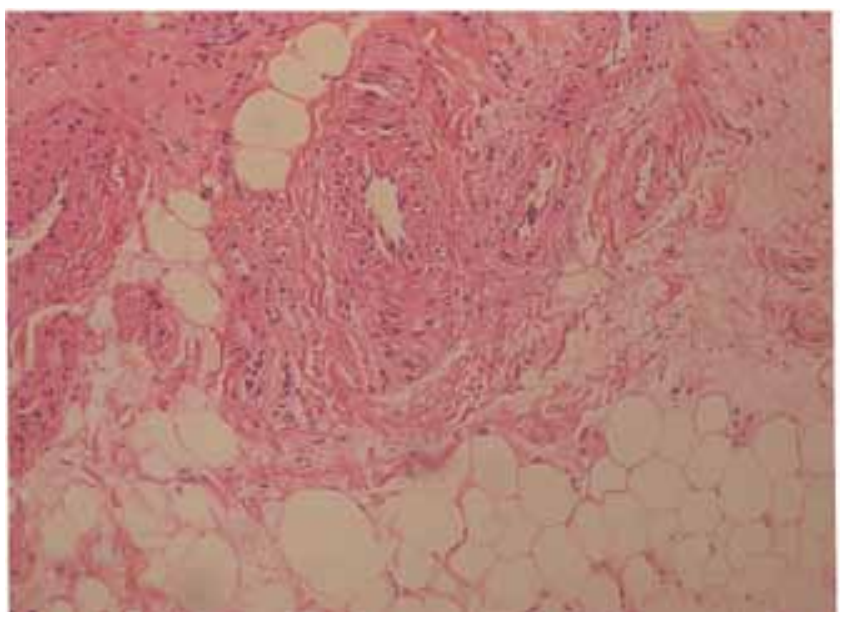

Figura 1A

Figura 1. adiposo unilocular y vasculatura arteriovenosa con 10x. En 1B mostrando la eosinofilia producto de la digestión enzimática con colagenasa en $10 \mathrm{X}$.

\section{Resultados}

La grasa infrapatelar en coloración de hematoxilina y eosina predigestión enzimática revela lóbulos de tejido adiposo unilocular entre los cuales se aprecia un estroma de tejido conectivo aerolar periadiposo celular y de tejido conectivo denso irregular entre lóbulos de tejido adiposo, este último continua con la túnica adventicia de vasculatura arterial, arteriolar y venular Figura 1A. Con digestión enzimática por colagenasa se aprecia fuerte eosinofilia relacionada con el producto de la digestión enzimática respetando la morfología de adipocitaria y vascular, Figura 1B.

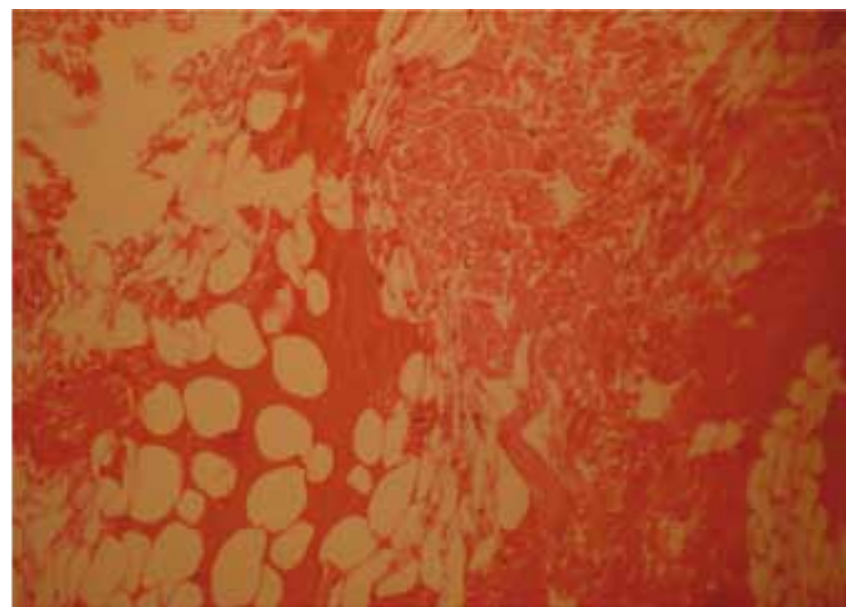

Figura 1B

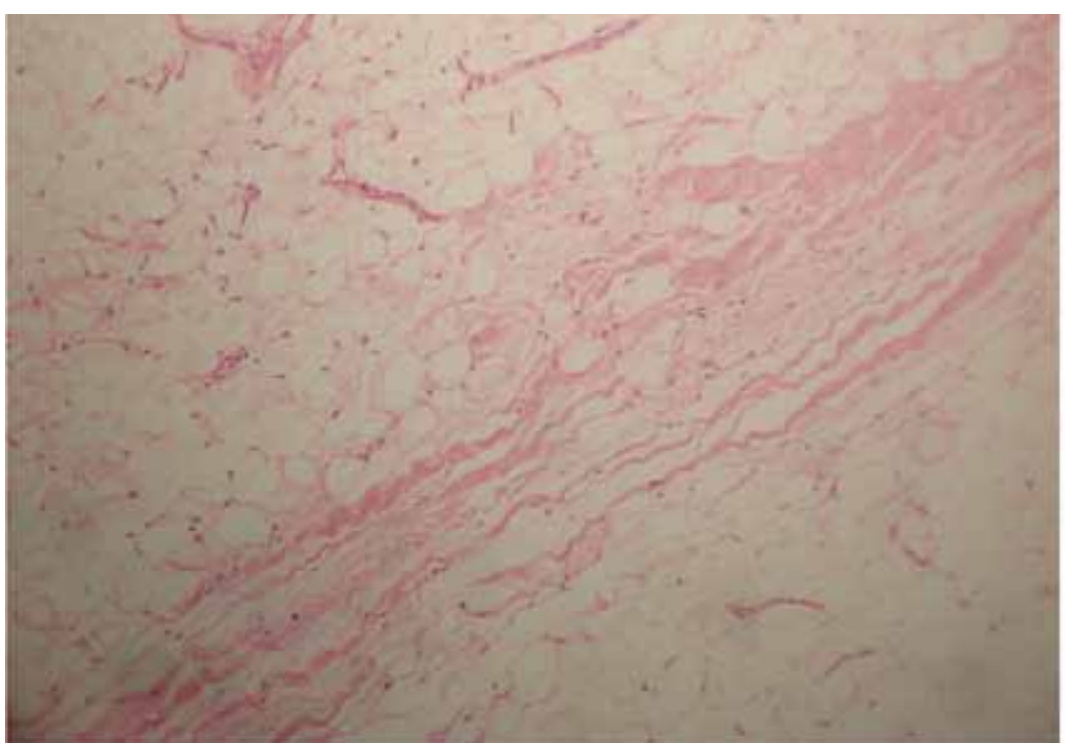

Figura 2A
Postdigestión enzimática son reconocibles las fibras elásticas por su homogénea eosinofília y forma ondulalada o "senoide" en distribución de "unidireccionalidad" formando agregaciones de fibras elásticas de aspecto "fascícular" cuya ubicación sobresale entre el tejido conectivo denso irregular descrito predisgestión Figura 2A, en el extremo y bordes de la distribución "fascicular" elástica descrita, las fibras elásticas ramifican continuando con la matriz extracelular del tejido conectivo aerolar laxo periadiposo Figura 2B.

Figura 2. Histología de la grasa infrapatelar en coloración de H\&E postdigestión con colagenasa En 2A mostrando fascículos de fibras elásticas eosinófilas onduladas en 5X. En 2B a 10 X en el extremo fascicular mostrando ramificaciones de fibras elasticas esparcidas en distribución difusa. 


\section{Diámetro fibras elásticas}

Tabla 1. Diámetro expresado en micras de las fibras elásticas intrafasciculares y perifasculares de la grasa infrapatelar

\begin{tabular}{ccc} 
& $\begin{array}{c}\mathrm{N}=120 \text { Fibras } \\
\text { Intrafasciculares }\end{array}$ & $\begin{array}{c}\mathrm{N}=120 \text { Fibras } \\
\text { Perifasciculares }\end{array}$ \\
\hline Promedio en micras & 5,56 & 3,15 \\
Desv. Est. & 1,42 & 1,77 \\
\hline
\end{tabular}

Por otra parte las pruebas de inmunocitoquimica e inmunofluoresencia arrojaron marcaje positivo para vimentina que es un marcador de tejido células del tejido conectivo como las células mesenquimales y adipocitos, y negativo para el resto de los anticuerpos estudiados, lo cual se corrobora con la morfología fibroblástica característica de estas células. En estos marcajes se pudo observar el grado de diferenciación de estas células, Figuras 3, 4 y 5.

\section{Discusión}

En la literatura es reconocida la presencia de tejido adiposo unilocular infrapatelarmente cuando se han hecho diagnósticos de fibroma infrapatelar (7), hemangioma infrapatelar (8), condroma infrapatelar (9) y lipoma infrapatelar (10) y en detalle se ha descrito la distribución de filetes nerviosos cuando se ha extraído de rodillas artrósicas (11). Sin embargo, no hay reportes en la literatura que demuestren histológicamente fibras elásticas y su distribución. Un cuidadoso estudio imagenológico funcional de Hamarneh et al con tomografía computarizada -CT- describe en la grasa infrapatelar cambios en los campos vectoriales al movimiento articular de extensión y flexión de la rodilla, adjudicando este hallazgo a un componente "elástico" de la grasa (14). Así mismo, Stevenson et al determina por imagenología CT y Resonancia Magnética -MRcambios graduales de la morfología de la grasa infrapatelar a diferentes ángulos de extensión y flexión de la rodilla, planteando la acomodación de la grasa infrapatelar a un componente "amortiguador elástico" (15).

En este estudio la particularidad de revelar fibras elásticas y por digestión con colagenasa demostrando además una distribución de unidireccional tipo "fascicular" permite adjudicar los cambios de forma de la grasa infrapatelar a los trabajos planteados

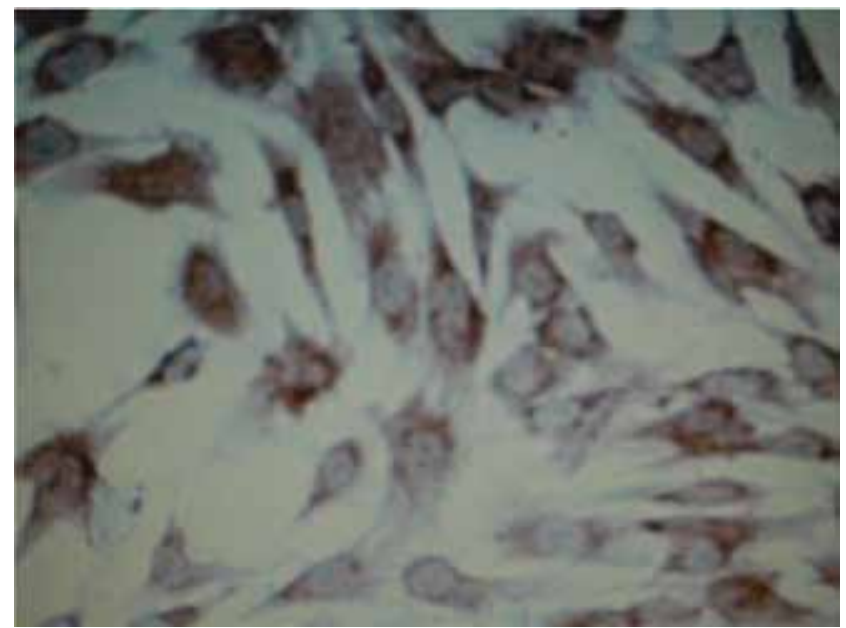

Figura 3. Células Mesenquimales derivadas de la Grasa Infrapatelar de Hoffa marcadas con anticuerpos contra vimentina y coloreadas con Diaminobencidina (DAB). Aumento 100X).

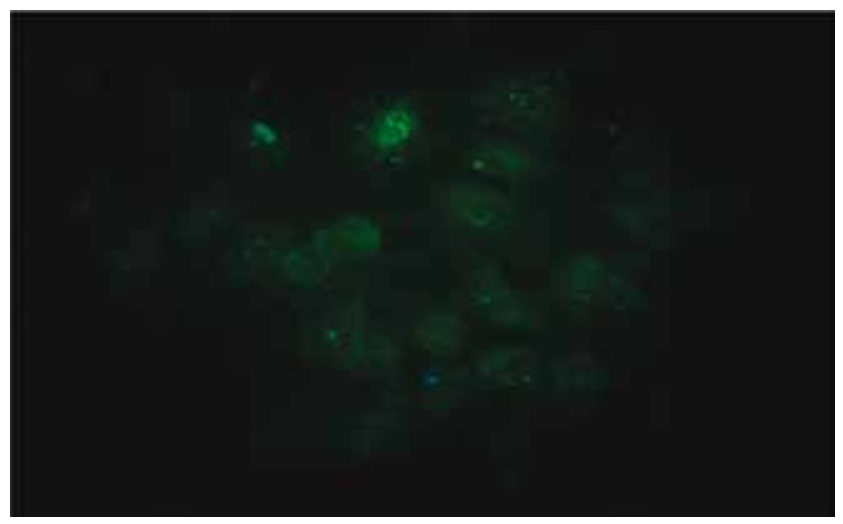

Figura 4. Células Mesenquimales derivadas de la Grasa Infrapatelar de Hoffa marcadas con anticuerpos con fluoresceína contra vimentina. (Aumento 100X).

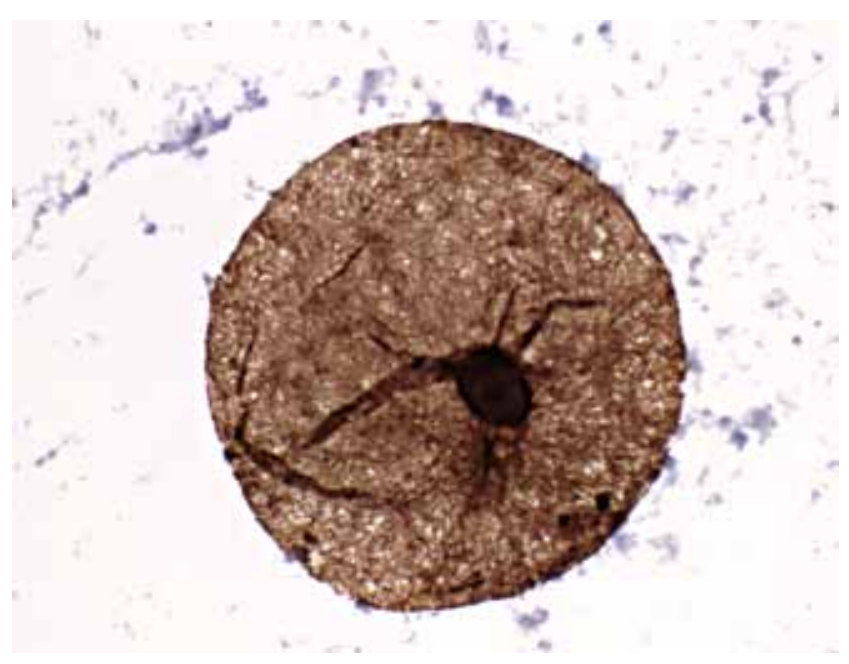

Figura 5. Adipocitos de la Grasa Infrapatelar de Hoffa marcados con anticuerpos contra vimentina y coloreadas con Diaminobencidina (DAB). (Aumento 1000X). 
por Hamarneh, et al (14) y Stevenson, et al (15) pues esta demostrado que los "fascículos" fibrosos elásticos juegan un rol funcional en la recuperación de la forma sin consumo energía luego de la deformación mecánica $(16,17)$. En cuanto al grosor y distribución de las fibras se reporta en la literatura agrupamiento y engrosamiento con en relación a la exigencia de su actividad $(18,19)$, en los conteos de fibras gruesas interfasciculares con promedio 5,56 micras y perifasciculares con grosores de 3,17 micras, Tabla 1. Llama la atención como las fibras perifasciculares mas delgadas se organizan en un patrón de distribución difuso esparciéndose entre la matriz extracelular adiposa, similar al característico patrón de distribución de fibras elasticas entre la matriz ósea que se halla en las entesis ligamentosas en los epicondilos del humero,(19) aspecto que podría correlacionar una distribución de fibras elasticas en la grasa infrapatelar con fines disipadores de tensión y acomodación de la superficie capsular sinovial al movimiento, similar al arreglo histológico de fibras colágenas y elasticas en la entesis del tendón de Aquiles del modelo murino, (20).

Finalmente la fenotipicación demostró la presencia de células mesenquimales en el tejido adiposo graso de Hoffa, por lo que debemos resaltar la importancia de este tejido como fuente de células mesenquímales para ensayos de terapia celular en patologías de origen articular.

Este trabajo ha sido financiado por la Dirección de Investigación de la Universidad de La Sabana proyecto Med-96-2008.

\section{Agradecimientos}

Los autores desean agradecer a la Srta. Tania López (técnico de la Clínica Universitaria de Navarra, Pamplona - España) su valiosa asistencia.

\section{Referencias}

1. The infrapatellar fat pad: anatomy and clinical correlations. J. Gallagher

2. P. Tierney, P. Murray, M. O'Brien. Knee Surg Sports Traumatol Arthrosc. 2005; 13: 268-272

3. MR Imaging of the Infrapatellar Fat Pad of Hoffa. Jon A. Jacobson,

4. Leon Lenchik,Michael K Ruhoy,Mark E. Schweitzer, Donald Resnick. RadioGraphics 1997; 17:675-691
5. Krebs VE, Parker RD. Arthroscopic resection of an extrasynovial ossifying chondroma of the infrapatellar fat pad: end-stage Hoffa's disease? Arthroscopy 1994;10:301-304.

6. Which is your diagnosis? R. B. Lourenço, M. B. Rodrigues. Radiol Bras 2007; 40(3):IX-X

7. MRI of Hoffa_s fat pad. D. Saddik, E. G. McNally, M. Richardson. Skeletal Radiol 2004; 33:433-444

8. Fibrous Scar in the Infrapatellar Fat Pad after Arthroscopy: MR Imaging.

9. Guangyu Tang, Mamoru Niitsu, Kotaro Ikeda, Hideho Endo, Yuji Itai Radiation Medicine: Vol. 18 No. 1, 1-5 p.p., 2000

10. Fibroma of tendon sheath of the infrapatellar fat pad. John Hur, Timothy A. Damron, Andrei I. Vermont. Sharad C. Mathur Skeletal Radiol.1999 28:407-410

11. Synovial hemangioma in Hoffa's fat pad (case report). Osman Aynaci, Ali Ahmetog $` u, A b d u l k a d i r$ Reis,Ahmet Ug ur Turhan. Knee Surg, Sports Traumatol, Arthrosc. 2001; $9: 355-357$

12. Extraskeletal ossifying chondroma in Hoffa's fat pad: an unusual cause of anterior knee pain. Case Report. Singh V K, Shah G, Singh P K, Saran D. Singapore Med J 2009; 50(5)

13. An unusual cause for anterior knee pain: strangulated intra-articular lipoma. Selcuk Keser, Ahmet Bayar, Gamze Numanoglu. Knee Surg Sports Traumatol Arthrosc 2005; 13: 585-588

14. Valoración anatomopatológica de los elementos neurales en la almohadilla grasa de Hoffa en rodillas artrósicas. $\mathrm{M}^{\mathrm{a}}$. J. Sangüesa Nebot, F. Cabanes Soriano, P. Alemany Monrabal, R. Fernández Gabarda, C Valverde Mordt.. Revista Española De Cirugía Osteoarticular 2004; 39 (217): 23-26.

15. Khan WS, Adesida AB, Tew SR, Andrew, Hardingham, TE. The epitope

16. Characterisation and the osteogenic differentiation potential of human fat pad derived stem cells is maintained with ageing in the later lifeInjury, Int J Care Injured 2009; 40:150 -157.

17. Wickham MQ, Ericsson GR, Gimble JM, Vail TP, Guilak, F.Multipotent Stromal Cells derived from the infrapatellar Fat Pad of the Knee, Clin Orthop 2003; 1 (412):196-212.

18. Deformation analysis of Hoffa's fat pad from CT images of knee flexion and extensión. Ghassan Hamarneh, Vincent Chu, Marcelo BordaloRodrigues and Mark Schweitzer. Proc. SPIE pages 5746- 527. 2005

19. Multi-angle deformation analysis of Hoffa's fat pad Kevin Stevenson, Mark Schweitzer, and Ghassan Hamarneh. . In SPIE Medical Imaging, volume 6143-29, pages 1-9, 2006.

20. A histological study of the deep fascia of the upper limb. Carla Stecco1,2 , Andrea Porzionato1, Veronica Macchi1 . Cesare Tiengo1., Anna Parenti3., Roberto Aldegheri2, Vincent Delmas4 . and Raffaele De Caro1. It. J. Anat. Embryol. Vol. 111, (2):1-6- 2006

21. Biochemisty of the elastic fibers in normal connective tissues and its alterations in diseases. Uitto J. J.Inv Derm. 1979 (72)1-10

22. A comparative study of aging of the elastic fiber system of the diaphragm and the rectus abdominis muscles in rats. C.J. Rodrigues,

23. Rodrigues Junior A.J. Braz J Med Biol Res 33(12) 1449-14542000

24. Molecular composition and pathology of entieses on the medial and lateral epycondyles of the humerus: a structural basis for epicondilitis. Milz S, Tisher T, Buettner A, Schieker M, Mair M, Redman S, Emery P, McGonalgle D, Benjamin M. Ann Rheum Dis 2004; 63 1015-1021

25. Adipose tissue at enthuses: the inervation and cell composition or the retromalleolar fat associated with the rat Achilles tendon. Shaw HM, Santer RM, Watson ADH Benjamin M. J Anat. 211(4) 436-443 